\title{
Factors Influencing the Nutraceutical Activity of Guava Fruits
}

\author{
Prachi Pathare, Smita Nilegaonkar and Vaishali Agte* \\ Agharkar Research Institute. G.G. Agarkar road, Pune 411004. \\ Email: vaishaliagte@hotmail.com
}

\begin{abstract}
Five different Indian varieties of guava fruits (Psidium guajava L.) collected as unripe, semi-ripe and fully ripe were analyzed for total phenols, vitamin $\mathrm{C}$ and antioxidant potential. Changes over 10 weeks time in the antioxidant potential in refrigerated guava juice were also investigated. The fruits contained appreciable diversity in vitamin C (43.0-278.3 mg/100g fresh weight), total phenol (97.9-542.7 mg/100g), DPPH scavenging capacity (60.5-98.4\%) and IC 50 of TEAC (2.18-5.16). A significant correlation existed between DPPH Scavenging capacity ( $\mathrm{r}=0.42$, $\mathrm{p}<0.05)$ and with total phenol and with TEAC and Vitamin $\mathrm{C}$ contents $(\mathrm{r}=-0.36, \mathrm{p}<0.05)$. Two way ANOVA indicated significant differences between varieties and maturation stages in the vitamin $\mathrm{C}$, polyphenols contents and TEAC $(\mathrm{p}<0.001)$. In guava juice, the levels of vitamin $\mathrm{C}$ and $\mathrm{DPPH}$ scavenging activity showed a sharp decrease with complete destruction after storage of 4 weeks at 5$10^{\circ} \mathrm{C}$. Levels of polyphenols and TEAC showed a slower decrease in the levels.
\end{abstract}

Keywords: Guava; TEAC; polyphenols; ascorbic acid; varietal differences.

\section{Introduction}

Plant foods contain a variety of phytonutrients and antioxidants like polyphenols, which are increasingly regarded as effective protective agents. Guava is one of the promising fruit rich in lectins, saponins, tannins, phenols, triterpenes, and flavonoids. High levels of vitamins, dietary fiber, carotenoids, altogether make guava therapeutically an important fruit. Consumption of guava fruit is reported to lower blood cholesterol, triglycerides, hypertension, and some cardiac problems $[1,2,3]$. Aqueous extracts from P. guajava have antioxidant or radical-scavenging activity. Most of the activity is associated with the polyphenols. However, the guava extracts also contain antioxidants such as ascorbic acid and carotenoids [4,5,6]. A 9-week study examined the effects of consuming guava $400 \mathrm{~g} /$ day on total antioxidant status and lipid profile (total cholesterol, triglycerides, low-density lipoprotein [LDL] and High- density lipoprotein [HDL] cholesterol). Consumption of guava reduced oxidative stress and blood cholesterol levels [7].

There are different guava fruit varieties present such as Lucknow 49, Allahabad Safeda, Chittidar, Harijha, Hafshi, Apple guava, seedless guava, Arka Mridula, Allahabad Surkha, Aurangabad guava.

The specific objectives were:

1.To study the diversity between different local variants of guava fruit for antioxidant potential

2.To assess the effect of the state of ripening of guava fruit on antioxidant potential

3.To study changes over time in the antioxidant potential in refrigerated guava juice

\section{Experimentals}

\subsection{Plant Materials}

Three different commonly consumed guava fruit types with white flesh were used viz. round smooth shape and medium size (Allahabad Safeda: G1), non-smooth oval shape and large (Lucknow 49:G2), small size and round shape (local country guava: G3). Additionally, two varieties with red flesh (Allahabad Surkha: G4 and Aurangabad guava G5) were also procured in three different ripening states. For each of the types, fruits of ripe, semi ripe and unripe state were purchased fresh from a local market of Pune, Maharashtra, when they were seasonally available, during the year of 2013. 
Initially, each fresh fruit type was washed under running tap water followed by washing with distilled water to remove the surface impurities. Unpeeled fruits of Allahabad Safeda were weighed (500g) and minced using a mixer grinder for preparing the juice.

\subsection{Chemicals and Reagents}

All chemicals and solvents used in the study were of analytical grade. 2, 2-diphenyl-1-picryl hydrazyl (DPPH) was purchased from Sigma. 2, 2-Azinobis (3-ethylbenzthiazoline-6-sulphonic acid) (ABTS) 6hydroxy-2, 5,7,8-tetramethylchroman-2-carboxylic acid (Trolox) was from obtained Aldrich. Ascorbic acid was procured from Hi-media India.

\subsection{Evaluation of in Vitro Antioxidant Activity Footnotes}

Vitamin C: Determination of vitamin $\mathrm{C}$ was done using reduction of 2, 6 dichlorophenol indophenol (DCPIP) as previously reported [8]. Fruit extracts for vitamin $\mathrm{C}$ analysis were obtained by homogenizing 0.1 gram of minced guava tissue (flesh and peel) in $2 \mathrm{ml}$ of $3 \%(\mathrm{w} / \mathrm{v}$ ) Meta phosphoric acid (w/v) in water for 3 hours. The homogenates were centrifuged at 15,000 rpm at $4^{0} \mathrm{C}$ for 10 minutes using centrifuge (Kubota, Japan). The supernatant was recovered and measured for vitamin C immediately. Vitamin C equivalents as DCPIP dye reducing potential at $520 \mathrm{~nm}$ were measured using UV-Visible Spectrophotometer (Schimadzu, Japan) and expressed as $\mathrm{mg}$ per $100 \mathrm{~g}$ of sample by comparison with the standard ascorbic acid.

Total phenol content: Total phenolic content was determined using the Folin-Ciocalteu's reagent. In brief, $2 \mathrm{~mL}$ of distilled water was pipetted into test tubes followed by $50 \mu \mathrm{L}$ of test sample extract as well as 20 to 100 all of standard tannic acid $(0.2 \mathrm{mg} / \mathrm{mL}) .100 \mu \mathrm{L}$ Folin Ciocalteau reagent $(1 \mathrm{~N})$ was added to each test tube except sample blank and the solutions were mixed thoroughly. After 30 seconds, $300 \mu \mathrm{L}$ of of Sodium carbonate $\left(20 \%\right.$ in distilled water) was added. The tubes were incubated at $37^{\circ} \mathrm{C}$ for $2 \mathrm{~h}$. The absorbance to blue chromospheres was measured at $700 \mathrm{~nm}$ [9]. The total phenolic concentration was calculated from a calibration curve by plotting $(0.2 \mathrm{mg} / \mathrm{mL})$ of tannic acid for absorbance at $700 \mathrm{~nm}$ and results were expressed as $\mathrm{mg}$ of tannic acid equivalents (TAE) per $100 \mathrm{gm}$ of sample.

DPPH Scavenging capacity: Measurement of DPPH (2, 2-diphenyl-1-picryl hydrazyl) radical scavenging activity was done [10] with slight modifications; $1 \mathrm{~mL}$ of DPPH reagent $(75 \mu \mathrm{M}$ in methanol) and $50 \mathrm{pL}$ of test samples in methanol were incubated at $37^{\circ} \mathrm{C}$ for $80 \mathrm{~min}$. Trolox $(0.1 \mathrm{mg} / \mathrm{mL})$ was adopted as a positive control and the reduction of the absorbance at $515 \mathrm{~nm}$ was monitored. A control reading was obtained using methanol instead of the extract. Free radical scavenging activity was expressed as \% Inhibition $=\left[\left(\mathrm{A}_{0}-\mathrm{A}_{1}\right) / \mathrm{A}_{0}\right] \mathrm{X} 100$ where, $\mathrm{A}_{0}$ is the absorbance of the control (without test samples) and $\mathrm{A}_{1}$ is the absorbance of test samples. Results have also been reported as IC50, which is the amount of antioxidant necessary to decrease the initial DPPH concentration by $50 \%$.

The Trolox equivalent antioxidant activity (TEAC): The TEAC was estimated using the $\mathrm{ABTS}^{+}$system [11]. The radical scavenging capacity of samples was evaluated against $\mathrm{ABTS}^{+}$generated by oxidizing a $5 \mathrm{mM}$ of ABTS (2, 2'-azinobis 3-ethylbenzothiazoline-6-sulfonic acid) diammonium salt, with manganese dioxide in PBS ( $\mathrm{pH}$ 7.4) at ambient temperature for 2 hours in dark. The reaction mixture contained $1.0 \mathrm{~mL}$ of $\mathrm{ABTS}^{+}$with an absorbance of 0.85 at $734 \mathrm{~nm}$ and $10 \mu \mathrm{L}$ of antioxidant testing sample extract in methanol or trolox $(0.1 \mathrm{mg} / \mathrm{mL}$ in methanol $)$ as a positive control. Calibration curve of Trolox $(0.1 \mathrm{mg} / \mathrm{mL})$ was plotted and results were expressed as $\mathrm{mg}$ of Trolox equivalent $\mathrm{ABTS}^{+}$ radical scavenging activity per $100 \mathrm{gm}$ of sample. Results have also been reported as IC50, which is the amount of antioxidant necessary to decrease the initial $\mathrm{ABTS}^{+}$concentration by $50 \%$.

\section{Results and Discussion}

Present study was undertaken on 5 different varieties of guava fruits collected in 3 different ripening states and analyzed for antioxidant potential. Five different varieties were Allahabad Safeda: G1, Lucknow 49:G2, local country guava: G3, Allahabad Surkha: G4, and Aurangabad guava: G5. 
As shown in Table 1a, G2 had higher content of vitamin $\mathrm{C}$ (278 mg/100 g fresh weight) than other types. Also, vitamin $\mathrm{C}$ values were lower in unripe state except for $\mathrm{G} 1$ which showed higher value in ripe state. Two way ANOVA for all 5 varieties indicated significant differences between varieties and between ripening states and their interaction $(\mathrm{F}=65$ and $68, \mathrm{p}<0.001)$. This suggests distinct differences between white and pink morphotypes and that a proper choice of variety and state of fruit needs to be chosen to get maximum benefit of its native vitamin $\mathrm{C}$ content. The values for unripe fruits and ripe fruits are similar to those reported $[12,13]$. As compared to ascorbic acid, phenolics are more stable molecules. Still, two way ANOVA for phenolics indicated highly significant differences between varieties and ripening states as well as interaction with ripening states $(\mathrm{p}<0.0001)$. G1 in ripe state had the highest phenolics while G4 had little difference between ripening states for the phenolics (Table 1a). However, in case of DPPH scavenging activity (Table 1a), G4 showed the highest activity but the differences between varieties or ripening states were not significant $(\mathrm{p}>0.1)$. TEAC was higher in $\mathrm{G} 2$ than the other fruits and two way ANOVA for TEAC as IC50 indicated highly significant differences between varieties and ripening states as well as interaction with ripening states $(\mathrm{p}<0.0001)$. The results suggest a large diversity in the values of phenolics as influenced by variety and ripening state. The correlations between the antioxidant parameters (Table 1b) indicated that TEAC was influenced by vitamin $\mathrm{C}$ contents while DPPH scavenging activity was associated with phenolics.

Table 1a. Antioxidant potential of 5 different varieties of guava fruits collected in 3 different ripening states

\begin{tabular}{l|l|l|l|l|l}
\hline Ripening stage & Type & $\begin{array}{l}\text { Vitamin C } \\
\mathbf{m g} / \mathbf{1 0 0 g}\end{array}$ & $\begin{array}{l}\text { Total phenol } \\
\mathbf{m g} / \mathbf{1 0 0 g}\end{array}$ & $\begin{array}{l}\text { DPPH \% } \\
\text { Scavenging } \\
\text { capacity }\end{array}$ & $\begin{array}{l}\text { TEAC } \\
\text { ABTS IC 50 }\end{array}$ \\
\hline & & Mean \pm S.D. & Mean \pm S.D. & Mean \pm S.D. & Mean \pm S.D. \\
\hline Unripe & G1 & $192.2 \pm 26.7$ & $122.0 \pm 8.5$ & $96.8 \pm 0.5$ & $2.19 \pm 0.00$ \\
\hline Semi ripe & & $118.3 \pm 13.4$ & $351.3 \pm 8.5$ & $96.8 \pm 0.3$ & $2.29 \pm 0.02$ \\
\hline Ripe & & $113.3 \pm 3.1$ & $542.7 \pm 1.9$ & $97.8 \pm 0.1$ & $2.75 \pm 0.00$ \\
\hline Unripe & G2 & $98.3 \pm 8.6$ & $162.0 \pm 4.7$ & $97.7 \pm 0.3$ & $1.62 \pm 0.00$ \\
\hline Semi ripe & & $79.8 \pm 7.9$ & $97.9 \pm 4.5$ & $72.0 \pm 9.3$ & $3.28 \pm 0.01$ \\
\hline Ripe & & $278.3 \pm 5.5$ & $228.7 \pm 25.5$ & $96.6 \pm 0.1$ & $1.72 \pm 0.00$ \\
\hline Unripe & G3 & $46.1 \pm 7.1$ & $148.6 \pm 1.5$ & $62.1 \pm 1.5$ & $2.69 \pm 0.00$ \\
\hline Semi ripe & & $137.0 \pm 1.0$ & $259.6 \pm 4.0$ & $60.5 \pm 3.2$ & $4.57 \pm 0.01$ \\
\hline Ripe & & $57.1 \pm 5.1$ & $173.6 \pm 0.5$ & $96.0 \pm 1.0$ & $3.84 \pm 0.01$ \\
\hline Unripe & G4 & $43.0 \pm 1.4$ & $350.9 \pm 2.5$ & $96.8 \pm 2.3$ & $2.71 \pm 0.00$ \\
\hline Semi ripe & & $88.0 \pm 5.6$ & $394.6 \pm 16.4$ & $98.4 \pm 0.8$ & $2.58 \pm 0.00$ \\
\hline Ripe & & $100.7 \pm 0.4$ & $376.8 \pm 3.8$ & $98.3 \pm 0.1$ & $4.15 \pm 0.01$ \\
\hline Unripe & G5 & $45 \pm 0.88$ & $143.64 \pm 4.29$ & $43.15 \pm 3.4$ & $7.02 \pm 0.01$ \\
\hline Semi ripe & & $66.87 \pm 7.07$ & $236.97 \pm 36.86$ & $14.21 \pm 0.73$ & $8.81 \pm 0.01$ \\
\hline Ripe & & $44.37 \pm 5.30$ & $107.27 \pm 4.29$ & $19.35 \pm 0.86$ & $5.6 \pm 0.01$ \\
\hline
\end{tabular}

Safeda: G1, Lucknow 49:G2, local country guava: G3, Allahabad Surkha: G4 and Aurangabad guava: G5

Table 1b. Correlation matrix of the study parameters

\begin{tabular}{l|l|l|l|l}
\hline & TEAC & VIT C & Phenolics & DPPH \\
\hline TEAC & 1 & -0.364 & 0.093 & -0.436 \\
\hline VIT C & & 1 & 0.042 & 0.286 \\
\hline Phenolics & & & 1 & 0.415 \\
\hline
\end{tabular}

Guava fruit is higher in vitamin $\mathrm{C}$ than citrus fruits ( $80 \mathrm{mg}$ of vitamin $\mathrm{C}$ in $100 \mathrm{~g}$ of fruit). The levels of total phenols and vitamin $\mathrm{C}$ as well as antioxidant potential at three different ripening stages (un-ripe, semi-ripe and fully-ripe) of guava (Psidium guajava L.) fruit collected from three different geographical regions of Pakistan have been reported [3]. 
The storage stability of guava juice at refrigerated conditions $\left(5-10^{\circ} \mathrm{C}\right)$ for the antioxidant potential was studied over a period of 10 weeks (Figure 1). The levels of vitamin C and DPPH scavenging activity showed a sharp decrease with complete destruction after 4 weeks whereas levels of polyphenols and TEAC however showed a slower decrease. Results indicate that although guava juice is rich in Vitamin $\mathrm{C}$, it loses the vitamin $\mathrm{C}$ activity faster during storage as compared to other antioxidants. Comparison of experimental guava juice with one branded guava juice indicated comparable values for vitamin $\mathrm{C}$ but higher values for TEAC, DPPH scavenging and polyphenols (Figure 2).

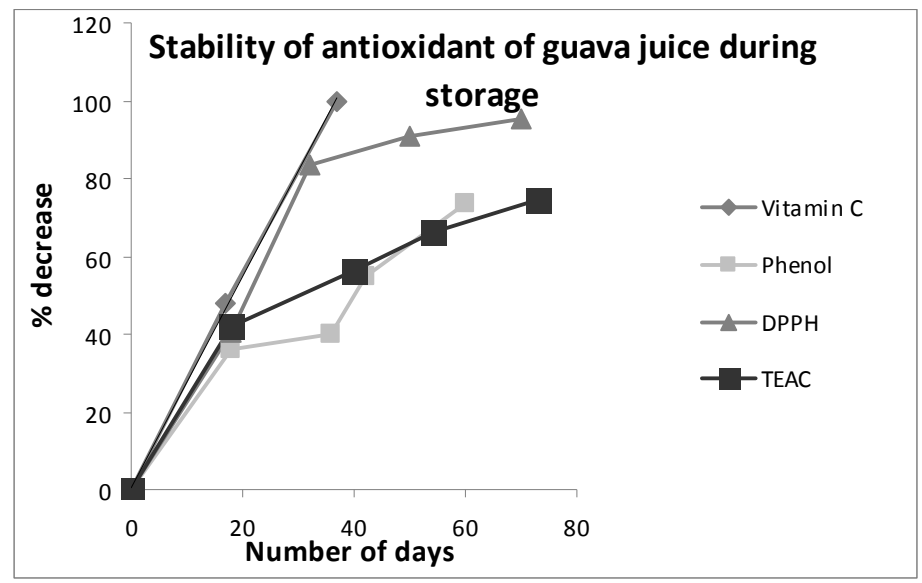

Figure 1. The storage stability of guava juice at refrigerated conditions for the antioxidant potential studied over a period of 10 weeks

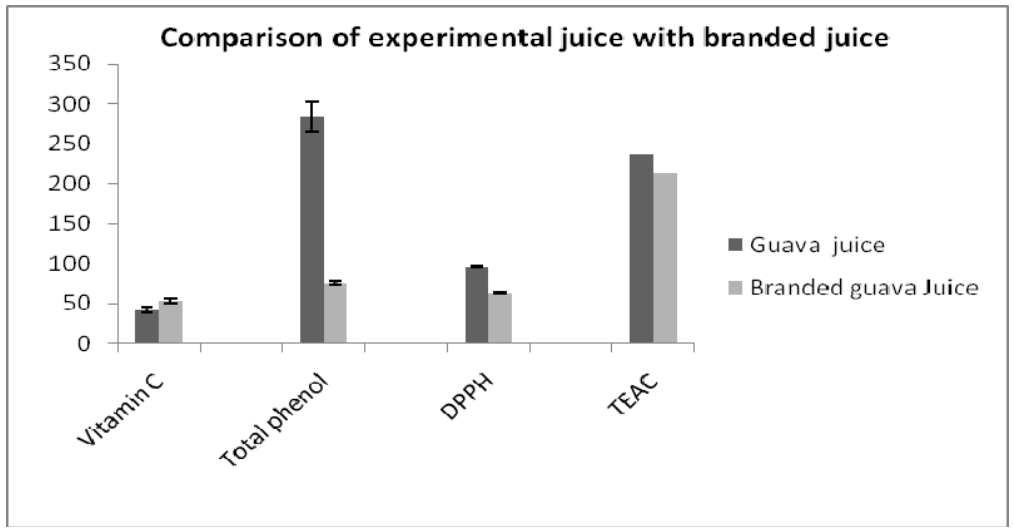

Figure 2. Comparison of antioxidant potential of experimental juice with branded juice. Vitamin $\mathrm{C}$ expressed in $\mathrm{mg} / 100 \mathrm{~g}$. Total phenol content expressed in mg/100g. DPPH Scavenging capacity expressed in \% inhibition. ABTS expressed as IC 50 value.

According to ancient Chinese Medicine, guava (Psidium guajava) is highly useful in the treatment of diabetes and other chronic diseases. However, the results regarding the anti-diabetic potential of guava fruit are ambiguous, clearly suggesting the need for further characterization for its hypoglycemic effects $[2,14]$. It is highly evident that the literature is inconclusive regarding the hypoglycemic and hypolipidemic effects of guava. One of the reasons could be the differences between varieties and maturity states used by different workers. It is likely that chemical composition analysis of guava constituents and factors influencing their levels will give further opportunity to develop a unique functional food based on guava. 


\section{Conclusions}

Overall, fruit at the un-ripe stage exhibited the highest levels of TPC, TEAC, reducing power and DPPH radical scavenging activity, followed by the semi-ripe and fully-ripe stages. On the other hand, vitamin $\mathrm{C}$ content increased as the fruit maturity progressed. These results supported the fact that different stages of maturation and geographical locations had profound effects on the antioxidant activity and vitamin $\mathrm{C}$ contents of guava fruit. Further, in spite of storage of guava juice in refrigerated conditions, it reduced the vitamin $\mathrm{C}$ contents rapidly.

Acknowledgements. This study was carried out as a part of the ICMR funded project (74/1/2011Pers/ EMS).

\section{References}

1. B. K. Biswas, N. A. Joshee, A. K. Yadav, "Development and application of biotechnology in guava: a nutraceutical fruit ishs Acta Horticulturae", International Symposium on Human Health Effects of Fruits and Vegetable, pp. 744, I, 2005.

2. J.T.Cheng, R.S. Yang, "Hypoglycemic effect of guava juice in mice and human subjects", Am J Chin Med, vol. 11, no. 1-4, pp. 74-76,1983.

3. J.Gull, B.Sultana, A F.nwar, R.Naseer, M.Ashraf, M.Ashrafuzzaman, "Variation in antioxidant attributes at three ripening stages of guava (Psidium guajava L.) fruit from different geographical regions of Pakistan" Molecules. Vo. 117 no. 3, pp. 3165-3180, 2012.

4. Jimenez-Escrig, A., Rincon, M., Pulido, R., Saura-Calixto F. Guava fruit (Psidium guajava L.) as a new source of antioxidant dietary fiber. J Agric Food Chem. Vol. 49, pp. 5489-5493, 2001.

5. S.Yamashiro, K.Noguchi, T.Matsuzaki, "Cardioprotective effects of extracts from Psidium guajava L and Limonium wrightii, Okinawan medicinal plants, against ischemia-reperfusion injury in perfused rat hearts", Pharmacology vol. 67, pp. 128-135, 2003.

6. H.Qian, V.Nihorimbere, "Antioxidant power of phytochemicals from Psidium guajava leaf", J Zhejiang Univ Sci. vol. 5, pp. 676-683, 2004.

7. A.Rahmat, M.Abu Bakar, N.Faezah, Z. Hambali, "The effects of consumption of guava (Psidium guajava) or papaya (Carica papaya) on total antioxidant and lipid profile in normal male youth", Asia Pac J Clin Nutr. Vol. 13(suppl), pp. 106, 2004.

8. Agte, V.V., Gokhale, M.K., Paknikar, K.M., Chiplonkar, S.A. Assessment of pearl millet vs rice based diets for bioavailability of four trace metals. Plant Foods for Human Nutrition, vol. 48, pp. 149-158, 1995.

9. Saucier, C. T.; Waterhouse, A. L. Synergetic activity of catechin and other antioxidants. J Agric Food Chem. Vol. 47, no. 11, pp. 4491-4494, 1999.

10. Yamaguchi F, Ariga T, Yoshimira Y, Nakazawa H. Antioxidant and anti-glycation of carcinol from Garcinia indica fruit rind. J Agric Food Chem, vol. 48 pp. 180-185, 2000.

11.Zielinska, D.; Szawara-N. D.; Ornatowska, A.; Wiczkowski, W. Use of cyclic voltammetry, photochemiluminescence, and spectrophotometric methods for the measurement of the antioxidant capacity of buckwheat sprouts. J Agric Food Chem. vol. 55 no. 24, pp. 9891-9898, 2007.

12.Lim yau yana, Lim theng teng, Tee jing jhi Antioxidant properties of guava fruit: comparison with some local fruits Sunway Academic Journal, vol. 3, pp. 9-20, 2006.

13.Luximon-Ramma, A., Bahorun, T., Crozier, A., Antioxidant actions and phenolic and vitamin C contents of common Mauritian exotic fruits. Journal of the Science of Food and Agriculture, vol. 83, pp. 496-502, 2003.

14.R.Roman-Ramos, J. L.Flores-Saenz, F. J. Alarcon-Aguilar, "Anti-hyperglycemic effect of some edible plants", J Ethnopharmacol. Vol. 48, no.1, pp. 25-32,1995. 